\title{
The Adult Consequences of Feminising Genital Surgery in Infancy. A Growing Skepticism
}

\author{
Sarah M. Creighton
}

Elizabeth-Garrett Anderson and Obstetric Hospital University College London Hospitals, Huntley Street, London,
WC1E 6DH, UK

\section{INTRODUCTION}

In contemporary management of the infant with ambiguous genitalia assigned to a female gender surgery plays a central role. Once the infant is assigned to a female sex of rearing, feminising genital surgery almost always follows in an attempt to restore normality. This management is now being challenged by adult patients and other medical and non-medical experts working in this field ${ }^{1-3}$. The debate is confusing both for patients who have undergone surgery and clinicians trying to offer the best care. There are many complex issues to consider before recommending surgery and it is essential that long-term outcome data are available to patients and their families making decisions about irreversible procedures. Clinicians must have a good knowledge of the current medical literature and should be very clear as to what is and is not supported by a reasonable evidence base.

Key words: Hermaphroditism, Genital Surgery

Address correspondence and requests for reprints to: Sarah M. Creighton, MD, FRCOG, Consultant Gynaecologist, Elizabeth-Garrett Anderson and Obstetric Hospital University College London Hospitals Huntley Street, London, WC1E 6DH, UK, Tel.: 004420-73-80-9565, e-mail: sarah.creighton@uclh.org

Received 03-08-04, Revised 15-09-04, Accepted 25-09-04

\section{The Role of Surgery}

Current standard practice in Europe and North America advocates feminising genital surgery for all children with ambiguous genitalia assigned to a female sex of rearing ${ }^{4,5}$. A standard infant feminising genitoplasty involves removal of some of the clitoris to reduce its size, construction of a vagina or opening the vaginal introitus and sometimes refashioning of the labia. In some European centres removal of the whole clitoris (clitorectomy) is still the procedure of choice for the enlarged clitoris ${ }^{6}$. Proponents of feminising genitoplasty in infancy cite both psychological reasons such as stable gender identity development and a better psychosexual and psychosocial outcome as well as physical reasons such as menstruation and sexual intercourse in later life. It is important for clinicians to know whether all or any of these outcomes are achieved and this information can only be obtained by well designed long-term follow-up studies.

\section{Available Data}

Unfortunately, there are few available objective, long-term outcome data from representative groups of intersex adults. Collection of data has been hampered by widespread policies of non-disclosure of diagnosis. Patients remain unaware of their diagnosis, unable to access medical or peer support and unavailable for recruitment in long-term follow-up studies. This practice is becoming less common but is still recommended policy in many centres. In addition, surgery for ambiguous genitalia is so widespread that it is difficult to recruit patients who have not had surgery. Most published studies are collections of small 
series - often by the operating surgeon - with variable outcome measures and indicators. Patient opinion largely remains absent and collaborative studies with patient groups are rare.

\section{Genital Surgery and Psychological Outcomes}

In the 1950's gender development was thought to be mainly a function of postnatal environmental factors. It was thought that babies are psychosexually neutral at birth and so have the potential to develop a male or female gender, depending on the way their parents treat them, on the appearance of their genitalia as male or female and on the way society perceives their gender and reacts to $\mathrm{it}^{7}$. On this basis, the optimal gender policy recommended that sex should be assigned solely on the basis of the external genital appearance as being suitable for male or female sexual function. Thus early genital cosmetic surgery became standard practice and has remained so since then. As the majority of intersex cases were felt to have inadequate male genitalia, infant feminising surgery became routine. It is clearer now that gender identity differentiation is a multifactorial process, involving prenatal influences and postnatal hormonal, social and psychological determinants ${ }^{8,9}$. The relative importance of external genital appearance in this process is unknown but may be minimal. The idea that one can stabilise gender development with infant cosmetic surgery has not been proven. In addition to gender stability, it has been claimed that feminising genitoplasty improves psychological outcomes. Most medical literature implies that psychological outcomes are better after cosmetic surgery and often recommend that gender assignment and surgery should be at an early age so that the children might never need to be aware that they were born with an intersex condition? There is, however, no available evidence showing that genital surgery improves psychological outcome. It has been suggested that all intersex children are at risk of psychological problems, irrespective of genital appearance and surgery and, if this is the case, then appropriate psychological support may be more useful than irreversible genital surgery

Relief of parental anxiety has also been cited numerous times as one of the prime indications for feminising surgery in childhood. However, this in fact depends upon the clinician's reassurance that surgery will ensure good outcomes. If parents are aware of the risks of surgery and the lack of evidence of good long-term outcomes, they may well not opt for surgery. Parental anxiety may still be relieved in many ways, including full information, contact with other families and expert psychological input.

\section{Genital Surgery Outcomes - Physical}

In order to utilise currently available outcome data, the endpoints of surgery should be defined and assessed consistently. Outcome measures should include cosmetic appearance, anatomical outcome (e.g. size of vagina, ability to insert tampon, possibility of penetrative intercourse), revision rate, complications, psychology and quality of life, sexual function and patient satisfaction.

In addition, other factors related to the condition may affect the outcome of surgery. For example, in congenital adrenal hyperplasia $(\mathrm{CAH})$, poor endocrine control leading to ongoing androgenic stimulation can result in further clitoromegaly and repeated surgical procures. In all children, the cosmetic appearance will change with age. The changes of puberty with pubic hair development and deposition of fat in the labia can result in a dramatic change. An enlarged clitoris in a pre-pubertal girl can look much less prominent after puberty. The patient's own opinion of surgery may be altered by her own body image, particularly if she has difficulties due to short stature or obesity.

\section{Current Outcome Data}

There is no standard methodology available for cosmetic assessment. Attention should be paid to the overall genital proportions and symmetry, distribution of pubic hair, size and shape of the clitoris, labia and introitus as well as the genital skin quality including scarring, rugosity and pigmentation. It is important to determine whether the cosmetic assessment has been made by the clinicians or by the patient as these may not concur. Where cosmetic appearance has been assessed, it is usually deemed poor with reports in the literature varying from 28 to $46 \%$ of women having an unsatisfactory appearance after clitoral surgery ${ }^{11,12}$ (Figure 1).

It is possible to have a good cosmetic outcome and yet still have a vagina too narrow for sexual intercourse. Vaginal stenosis is the main anatomical problem and is common, occurring in $36 \%$ to $100 \%$ following surgery in infancy ${ }^{11,13}$. 


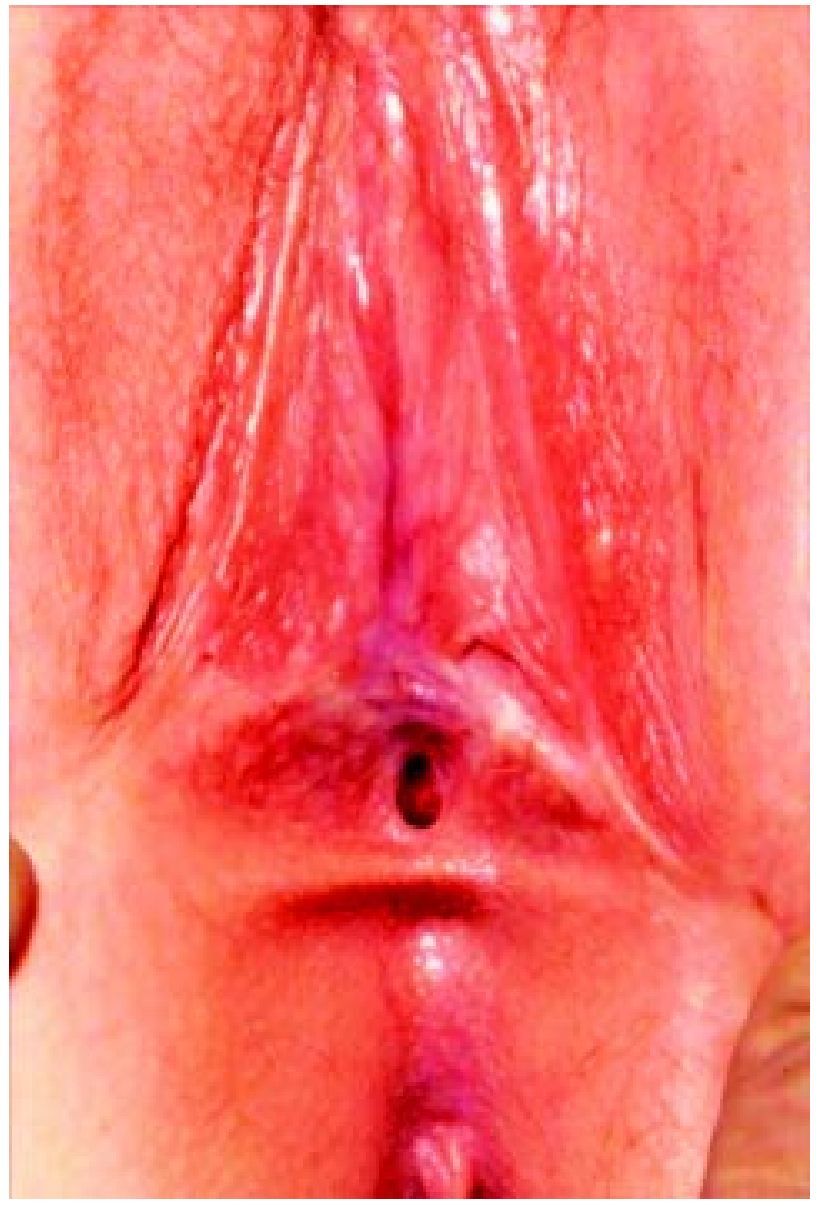

Figure 1. A 14 year old girl with Congenital Adrenal Hyperplasia. She has had two feminising genitoplasties prior to menarche. The perineum is scarred and the clitoris absent. She now presents because she was unable to use tampons for menstruation. The vagina is stenosed and she will require further surgery for tampon use and intercourse.

Even after a "one stage" genitoplasty, revision surgery at adolescence is frequently necessary and the family should be prepared for this. Revision surgery is necessary for both the clitoris and the vagina, for the clitoris up to $44 \%$ and for the vagina up to $80 \%{ }^{14,15}$.

\section{Genital Surgery - Sexual Outcomes}

The clitoris is an erotically important sensory organ and its only known function is in contributing to female orgasm. Recent work on the innervation of the clitoris has demonstrated nerves surrounding the tunica with multiple perforating branches entering the dorsal aspect of the corporeal body and glans ${ }^{16}$. Any incision to the clitoral glans, corpora or hood may damage the innervation. There are numerous surgi- cal papers on clitoral surgery; however, only a few provide follow-up data on psychosexual outcomes.

Two studies have looked in more detail at psychosexual function in Intersex women after Congenital Adrenal Hyperplasia (CAH) and both studies found that the CAH group were less likely than their sisters to be sexually active and more likely to experience orgasmic dysfunction ${ }^{17,18}$. A third study assessed sexual function in adult women with a history of ambiguous genitalia due to a mixture of intersex diagnosis. Some of these women had undergone clitoral reduction and some had not had surgery ${ }^{18}$. Overall sexual function scores were poor in both groups when compared to a standard population of women; however, there were also significant differences between the two groups. Those who had undergone clitoral surgery were significantly less likely to achieve orgasm compared with those who had not had surgery. This study suggested that cosmetic surgery to the clitoris does not ensure improved adult sexual function and in fact clitoral surgery may cause damage. This has been confirmed recently by a study which measured clitoral and vaginal sensation in adult women with $\mathrm{CAH}$ who had undergone childhood genital surgery. Pilot data demonstrated markedly impaired sensation when compared to normal controls ${ }^{20}$. Sensory input from the genitals is a major contributory factor for female arousal and sexual pleasure and is altered adversely by clitoral surgery. This work demonstrated adverse effects of surgery on both clitoral sensation and sexual function.

It is accepted that the majority of clinicians and families would wish to assign a sex of rearing to a baby born with ambiguous genitals. Realistically, in our current society the child needs to be assigned to one of the two genders on offer. What needs re-evaluation, however, is the automatic progression to subsequent feminising genital surgery to reinforce that choice. It is clear from the literature that neither genital appearance nor genital surgery has a confirmed role in ensuring gender stability or indeed any other positive psychological outcome. There is increasing evidence that surgery has a high risk of long term complications, that repeat procedures are frequent and that sexual sensation and sexual function may be damaged. Although the majority of patients have not sought to change the gender selected for them by their doctors $^{21}$, this does not mean that they are all satis- 
fied. Irreversible infant genital surgery deprives patients of choice in later life.

\section{Reproductive Technologies}

The area of reproductive medicine is advancing rapidly and some of these innovations may affect sex assignment and the role of genital surgery. Female sex assignment and subsequent feminizing genital surgery is usually chosen for babies with ambiguous genitals and an XY karyotype because of the poor outcome of penile reconstructive surgery. Multiple reconstructive techniques used in the past have poor results and the function of such patients is poor in terms of erection and ejaculation. However, recent advances in tissue engineering have demonstrated the possibility of growing penile tissue and may well challenge the popularity of female sex assignment in future. The corpus cavernosum is the most difficult part of the penis to reconstruct as it has complex functions, but researchers have grown varying lengths of rabbit corpus cavernosum in the laboratory ${ }^{22}$. If this technique works in humans, it could make possible penile enlargement in XY males with aphallia and micropenis. Even at this present time, clinicians would still need to demonstrate that assignment of these boys to female is better than leaving them as boys. It has been surmised that having a micropenis would put boys and men at risk of psychological difficulties, although the few studies available on men with micropenis have failed to find the predicted high levels of sexualityrelated emotional and behavioural difficulties ${ }^{23}$.

\section{Fertility}

The ability to reproduce has always been a key factor in sex assignment. In some conditions the decision seems relatively simple; for example, women with $\mathrm{CAH}$ are able to conceive and bear children, though their fertility potential depends on good steroid control. Fertility potential is seen as an overwhelming benefit and even most virilised girls of Prader stage 5 are assigned to a female sex of rearing if diagnosed at birth. XY babies with ambiguous genitals are usually assigned a female sex of reaving, as it has been assumed that they are infertile whether male or female. With increasing development of fertility techniques, however, this is no longer the case. The advent of ICSI (intracytoplasmic sperm injection) in 1992 has led to pregnancies even in the presence of oligo or even azoospermia ${ }^{24}$.ICSI involves injection of a single sperm into the oocyte. Spermatozoa can be aspirated from the testis or epididymis and can be used fresh or cryopreserved for later use. There have been cases reported of successful pregnancies in conditions previously labelled as infertile. For example, 5-alpha reductase deficiency males have previously been considered infertile. They have a low sperm volume with high viscosity as well as oligo or azoospermia associated with undescended testes and the sequelae of multiple genital operations. However, pregnancies have been reported in this group both spontaneously and using fertility techniques such as intrauterine insemination and ICSI $^{25}$.

\section{CONCLUSION}

It is time to re-evaluate the role of genital surgery in the management of ambiguous genitalia. Although initial cosmetic results can be good and this may reassure both parents and clinicians, there is very little evidence of satisfactory post-pubertal cosmetic or anatomical outcomes. Surgical revision of the vagina to allow tampon use and intercourse is necessary in over $80 \%$ of patients. If vaginal surgery were deferred, it would limit the total number of operations for each individual and may lessen the incidence of fibrotic introital stenosis. It is now clear that clitoral surgery has indeed an impact upon sexual function, although the magnitude of this effect needs further evaluation. In the absence of clear evidence that infant feminising genital surgery improves psychological outcome, the choice of deferring genital surgery must be discussed with the family.

This is an extremely difficult area of practice and no consensus amongst clinicians has yet been reached. Each case must be considered individually with a clear commitment to transparency of discussion including possible detrimental effects upon future sexual function. Adequate and informed long-term psychological support should be available to all families whether or not they elect to have surgery. Prospective collaborative long-term outcome studies are desperately needed to help both families and their doctors make these almost impossible choices.

\section{REFERENCES}

1. Dreger AD, 1998 “Ambiguous sex" - or ambivalent medicine? Ethical issues in the treatment of intersexuality. 
Hastings Cent Rep 28: 24-35.

2. Kessler SJ, 1990 Lessons from the intersexed. New Brunswick, New Jersey: Rutgers University Press.

3. Phornphutkul C, Fausto-Sterling A, Gruppuso PA, 2000 Gender self-reassignment in an XY adolescent female born with ambiguous genitalia. Pediatrics 106: 135-137.

4. Consensus statement on 21-hydroxylase deficiency from the Lawson-Wilkins pediatric endocrine society and the European Society for Paediatric Endocrinology. $2002 \mathrm{~J}$ Clin Endocrin Metab 87: 4048-4053.

5. Nihoul-Fekete C, 2004 Surgical management of the intersex patient and overview in 2003. J Ped Surg 39: 144-5.

6. Riepe FG, Krone N, Viemann M, Partsch CJ, Sippell WG, 2002 Management of congenital adrenal hyperplasia: results of the ESPE questionnaire. Horm Res 58: 196-205.

7. Money J, Hampson JG, Hampson JL, 1955 Hermaphroditism: recommendations concerning assignment of sex, change of sex and psychologic management. Bull Johns Hopkins Hosp 97: 284-300.

8. Meyer-Bahlburg HFL, 1998 Gender Assignment in Intersexuality. J Psychol Hum Sex 10: 1-21.

9. Zucker KJ, 1999 Intersexuality and gender identity differentiation. Annu Rev Sex Res 10: 1-69.

10. Engert J, 1989 Surgical correction of virilised female external genitalia. Prog Pediatr Surg 23: 151-164.

11. Alizai NK, Thomas DFM, Lilford RJ, Batchelor AGG, Johnson N, 1999 Feminizing genitoplasty for congenital adrenal hyperplasia: What happens at puberty? J Urol 161: 1588.

12. Krege S, Walz KH, Hauffa BP, Korner I, Rubben H, 2000 Long term follow-up of female patients with congenital adrenal hyperplasia from 21-hydroxylase deficiency with special emphasis on the results of vaginoplasty. BJU Int 86: $253-8$.

13. Creighton SM, Minto CL, Steele SJ, 2001 Objective cosmetic and anatomical outcomes at adolescence of feminising surgery for ambiguous genitalia done in childhood. Lancet 358: 124-125.

14. Newman K, Randolph J, Anderson K, 1992 The surgical management of infants and children with ambiguous gen- italia. Lessons learned from 25 years. Ann Surg 215: 644653.

15. Bailez MM, Gearhart JP, Migeon C, Rock J, 1992 Vaginal reconstruction after initial construction of the external genitalia in girls with salt-wasting adrenal hyperplasia. J Urol 148: 680-682.

16. Baskin LS, Erol A, Li YW, Liu WH, Kurzrock E, Cunha GR, 1999 Anatomical studies of the human clitoris. J Urol 162: 1015-1020.

17. Dittmann RW, Kappes ME, Kappes MH, 1992 Sexual behavior in adolescent and adult females with congenital adrenal hyperplasia. Psychoneuroendocrinology 17: 153170 .

18. May B, Boyle M, Grant D, 1996 A comparative study of sexual experiences. Journal of health psychology 1: 479492.

19. Minto CL, Liao KL, Woodhouse CRJ, Ransley PG, Creighton SM, 2003 Sexual outcomes in intersex conditions with ambiguous genitalia: the effects of clitoral surgery. Lancet 361: 1252-7.

20. Crouch NS, Minto CL, Laio LM, Woodhouse CRJ, Creighton SM, 2004 Genital sensation following feminising genitoplasty for Congenital Adrenal Hyperplasia; a pilot study. BJUI 93: 135-8.

21. Migeon CJ, Wisniewski AB, Brown TR, et al, 2002 46XY intersex individuals: phenotypic and etiologic classification, knowledge of condition and satisfaction with knowledge in adulthood. Pediatrics 110.

22. Kwon TG, Yoo JJ, Atala A, 2002 Autologous penile corpora cavernosa replacement using tissue engineering techniques J Urol 164: 1754-8.

23. Reilly JM, Woodhouse CRJ, 1989 Small penis and the male sexual role. J Urol 142: 569-571.

24. Palermo G, Joris H, Devroey P, Van Sterteghem, 1992 Pregnancies after intracytoplasmic injection of a single spermatozoon into an oocyte. Lancet 340: 12-8.

25. Katz MD, Kligman I, Li-Qun C, et al, 1997 Paternity by intrauterine insemination with sperm from a man with 5alpha reductase 2 deficiency. N Engl J Med 336:994-997. 